nốt dạng kính mờ vùng ngoại vi, sau tiến triển lan thành các đám, mảng, lan từ ngoại vi vào trung tâm. Một số báo cáo khi sinh thiết phổi ở bênh nhân COVID-19 tử vong thì tổn thương chủ yểu ở phế nang là tổn thương lan toả với dịch tiết và lympho bào cũng như đại thực bào, được cho là có liên quan đến hình ảnh các tổn thương kính mờ trên phim chụp phổi.

\section{KẾT LUÂ̂N}

- 71 bệnh nhân trong nghiên cứu, tuổi trung bình là 39,5 tuổi, nam và nữ gặp tương đương nhau. Thời gian ủ bệnh trung bình của bệnh nhân COVID-19 là 6,53 $\pm 4,07$ ngày. Thời gian thanh thải virus: $8,22 \pm 4,83$ ngày. Thời gian sạch KST sốt rét trong máu là 4,18 $\pm 2,09$ ngày. $100 \%$ bệnh nhân điều trị khỏi.

- Triệu chứng sốt hay gặp ở nhóm sốt rét $(90,1 \%)$, cao hơn nhóm COVID-19 (45\%). Ho gặp chủ yếu ở nhóm BN COVID-19. Không nên bỏ qua bệnh sốt rét trong vụ dịch COVID-19 nếu bệnh nhân có yếu tố dịch tễ đi về từ vùng dịch

- Giảm tiểu câuu và rối loạn đông máu là các biểu hiện thường gặp ở bệnh nhân sốt rét. Tăng $\mathrm{PCT}$ và $\mathrm{CRP}$ ở bệnh nhân sốt rét nhiều hơn ở bệnh nhân COVID-19 nhe

$-75 \%$ bệnh nhân có tổn thương phổi trên phim CT ngực, chủ yếu tổn thương 2 bên ( $80 \%)$
TÀI LIỆ THAM KHẢO

1. WHO, Rolling update on coronavirus diseases (COVID-19). 2020.

2. Wei-jie Guan, P.D., et al., Clinical characteristics of 2019 novel coronavirus infection in China. medRxiv preprint doi: https://doi.org/ 10.1101/2020.02.06.20020974, 2020.

3. World Health Organization, WHO World Malaria Report 2019. [(accessed on 16 July 2020)]; Available online: https://www.who.int/ publications/i/item/9789241565721.

4. Chaolin Huang*, et al., Clinical features of patients infected with 2019 novel coronavirus in Wuhan, China. The Lancet 2020( https://doi.org/10.1016/S0140-6736(20)30183-5).

5. Nanshan Chen*, et al., Epidemiological and clinical characteristics of 99 cases of 2019 novel coronavirus pneumonia in Wuhan, China: a descriptive study. The Lancet, 2020(Published online January 29,2020 https://doi.org/10.1016/S0140-6736(20)30211-7).

6. Wu, Y.C., C.S. Chen, and Y.J. Chan, Overview of The 2019 Novel Coronavirus (2019-nCoV): The Pathogen of Severe Specific Contagious Pneumonia (SSCP). J Chin Med Assoc, 2020.

7. Di Gennaro, F., et al., Malaria and COVID-19: Common and Different Findings. Tropical medicine and infectious disease, 2020. 5(3): p. 141.

8. da Rosa Mesquita, R., et al., Clinical manifestations of COVID-19 in the general population: systematic review. Wiener klinische Wochenschrift, 2021. 133(7-8): p. 377-382.

\title{
THIẾU KẼM VẤN ĐỀ Ý NGHĨA SỨC KHỎE CộNG ĐỒNG VÀ MộT SỐ YẾU TỐ LIÊN QUAN Ở PHỤ NỮ TUỔI SINH ĐỂ TẠI MộT TỈNH VÙNG TÂY BẮC Bộ, NĂM 2018
}

\author{
Nguyễn Song Tú ${ }^{1}$, Hoàng Văn Phương ${ }^{2}$, \\ Nguyễn Hồng Trường ${ }^{1}$, Trần Thúy $\mathrm{Nga}^{1}$, Hoàng Long Quân ${ }^{3}$
}

\section{TÓM TẮT}

Trong nhiều thập kỷ qua, thiếu kẽm là một tình trạng thiếu vi chất dinh dưỡng phổ biến nhất ở Việt Nam. Nghiên cứu mô tả cắt ngang tiến hành trên 809 phụ nữ 15 - 35 tuổi tại Sơn La, thuộc khu vực Tây Bắc Bộ để xác định tịnh trạng thiếu kẽm và một số yếu tổ liên quan. Kết quả cho thấy tỷ lệ thiếu kểm ở phụ nữ $15-35$ tuổi là $86,8 \%$. Nồng độ kẽm huyết thanh trung bình là $9,56 \pm 1,5 \mu \mathrm{mol} / \mathrm{L}$. Tỷ lề thiếu kẽm ở nhóm 15 - 24 là 84,0\% thấp hơn có ý nghĩa

${ }^{1}$ Viện Dinh dưỡng Quốc gia, Hà Nội

'Cực Y tế dự phòng, Bộ Y tế

${ }^{3}$ Trường Đại hoc Y Hà Nội

Chịu trách nhiệm chính: Nguyễn Song Tú

Email: nguyensongtu@yahoo.com

Ngày nhận bài: 14.6.2021

Ngày phản biện khoa học: 9.8.2021

Ngày duyệt bài: 16.8.2021 thống kê so với nhóm 25 - 35 tuổi $(89,1 \%)$. Có tương quan thuận chiều giữa nồng độ hemoglobin và retinol huyết thanh với nồng độ kễm huyết thanh $(p<0,01)$. Thiếu năng lượng trường diễn, tình trạng vitamin $A$ và tiền sử sốt có liến quan đối với tình trạng thiếu kẽm $(p<0,05)$. Thiếu kẽm là vấn đề có ý nghĩa sức khỏe cộng đồng nghiêm trọng ở phụ nữ tuổi sinh đẻ tỉnh Sợn La, cần có giải pháp tích cực và tổng thể trong cải thiện tình trạng thiếu kẽm nói riêng và phối hợp phờng chống thiếu vi chất dinh dưỡng nói chung tại các vùng miền núi, đặc biệt vùng nghèo, vùng khó khăn.

Tư khoá: thiếu kẽm, thiếu vi chất dinh dưỡng, phụ nữ tuổi sinh đẻ, yếu tố liên quan

\author{
SUMMARY \\ ZINC DEFICIENCY IS A PUBLIC HEALTH \\ PROBLEM AND SOME RELATED FACTORS \\ IN WOMEN OF REPRODUCTIVE AGE IN A \\ PROVINCE IN THE NORTH WEST REGION, 2018
}


For decades, zinc deficiency has been the most common micronutrient deficiency in Vietnam. A crosssectional study was conducted on 809 women aged 15-35 years old in Son La, in the Northwest region to determine zinc deficiency and some related factors. Results showed that the prevalance of zinc deficiency in women $15-35$ years old was $86.8 \%$. The mean serum zinc concentration was $9.56 \pm 1.5 \mu \mathrm{mol} / \mathrm{L}$. The prevalence of zinc deficiency in the group 15-24 was $84.0 \%$ statistically significant lower than that in the group of $25-35$ years old $(89.1 \%)$. There was a positive correlation bettwen hemoglobin concentration and serum retinol with serum zinc concentration $(p<$ 0.01 ). Chronic Energy deficiency, vitamin A status and history of fever were related to the zinc deficiency status $(p<0.05)$. Zinc deficiency is a serious public health problem in women of reproductive age in Son La province. There is a need for positive and comprehensive solutions to improve zinc deficiency in particular and combination the micronutrient deficiencies in general in mountainous areas, especially in poor and disadvantaged areas.

Keywords: zinc deficiency, micronutrient deficiency, women of reproductive age, related factors

\section{I. ĐĂT VẤN ĐỀ}

Trên thế giới và Viêt Nam, thiếu kẽm là một tình trang thiếu vi chất dinh dưỡng phổ biến, có ý nghĩa sức khỏe cộng đồng (YNSKCĐ). Nguyên nhân cơ bản nhất khiến tỷ lệ thiếu kẽm cao là do cơ thể con người không thể dự trữ kẽm, do đó sự thiếu hưt có thể phát sinh nhanh chóng do chế độ ăn uống không hợp lý, hoặc nhu cầu kẽm tăng cao do yếu tố sinh lý hoặc mắc nhiếm khuẩn. Ước tính có khoảng $17,3 \%$ dân số thế giới có nguy cơ thiếu kẽm [1]. Thiếu kẽm ảnh hưởng đến hơn 2 tỷ người ở các nước phát triển. Tỷ lệ thiếu kẽm ở phụ nữ tuổi sinh đẻ (PNTSĐ)là rất cao nhưng khác biêt giữa các nước như Ethiopia (2017) là 34\%, Cameroon là 81,6\% [2], Vùng trung tâm của Kongo của Công Gô (2016) là $58,0 \%$, ở phụ nữ nông thôn ở Ấn Độ (2011) là $52 \%$, ở phụ nữ không mang thai và không cho con bú Bangladesh (2017) là (57\%). Ở Viêt Nam điều tra quốc gia 2010 cho thấy tỷ lệ thiếu kẽm PNTSĐ rất cao $67,2 \%$, không khác biệt giữa nông thôn và thành thị [3]; Tỷ lệ thiếu kẽm ở PNTSĐ chung trong điêu tra 3 miền của Viêt Nam giảm chậm, điêu tra năm 2015 cho thây là $63,6 \%$, trong đó nông thôn là $60,3 \%$ và miền núi là $73,4 \%$ ở mức cao có YNSKCĐ [4]. Thiếu kẽm có thể làm suy giảm chức năng miễn dịch và góp phần vào gánh nặng toàn cầu của các bệnh truyền nhiễm bao gôm tiêu chảy, viêm phổi và̀ sốt rét (Ackland $M L, 2016)$. Các yếu tố liên quan đến tình trạng thiếu kẽm như chế độ ăn, nhóm tuổi, tình trạng sinh lý hoặc sự xuất hiện của bệnh lý; hay khu vực địa lý thường gặp ở vùng nông thôn; hoàn cảnh kinh tế [2]. Ăn ít thức ăn nguồn gốc động vật và chế độ ăn không đủ đa dạng (Berhe K); chỉ số chất lượng nhà ở, chỉ số chu vi vòng cánh tay cũng là yếu tố được kể đến.

Phụ nữ tuổi sinh đẻ vùng nghèo, vùng miền núi thường là đối tượng có nguy cơ thiếu kẽm cao do chế độ ăn nghèo nàn và nhu cầu tăng cao hơn về chất dinh dưỡng trong giai đoan mang thai và nuôi con bú. Chuẩn bị cho thể chất tốt và dinh dưỡng đầy đủ cho phụ nữ giai đoạn tiền mang thai cũng rất quan trong. Để có đinh hướng can thiệp phù hợp cho đối tượng này, nghiên cứu được tiến hành nhằm đánh giá thực trạng thiếu kẽm và những yếu tố liên quan ở PNTSĐ vùng miền núi của một tỉnh Tây Bắc Bộ.

\section{II. ĐỐI TƯợNG VÀ PHƯƠ'NG PHÁP NGHIÊN CứU 2.1 Đối tượng nghiên cứu \\ Tiêu chuẩn lựa chon: Phu nữ độ tuổi 15-} 35, không nuôi con bú < 12 tháng hoặc không có thai. Đồng ý tham gia.

2.2. Địa điểm và thời gian nghiên cứu

Tại 10 xã của huyện Thuận Châu và Mường La, tỉnh Sơn La trong thời gian từ tháng 07/2018 đến tháng 12/2018.

2.3. Thiết kế nghiên cứu. Mô tả cắt ngang

2.4. Cỡ mẫu: Ap dụng công thức:

$$
\mathrm{n}=\frac{\mathrm{z}^{2}(1-\mathrm{a} / 2) \times \mathrm{p}(1-\mathrm{p}) \times \mathrm{DE}}{\mathrm{d}^{2}}
$$

Trong đó: n là số đối tượng cân điều tra, p là tỷ lê thiếu kẽm ở phụ nữ vùng miền núi năm 2015 là 73,4\% [4]; chọn $d=0,05 ; z$ có giá trị là 1,96 (301 đối tượng). $\mathrm{DE}=1,3$; Cõ mẫu cần chung là 391 đối tượng x 2 huyện x 5\% bỏ cuộc $=821$ đối tượng. Thực tế điều tra 809 đối tượng.

\subsection{Phương pháp chọn mẫu}

Chọn tỉnh: Chọn chủ đích huyện Thuận Châu và Mường La, tỉnh Sơn La một tỉnh miền núi phía Bắc, nơi có hoàn cảnh kinh tế khó khăn.

Chọn xã: Chọn ngẫu nhiên đơn $5 / 9$ xã thuộc xã nghèo, huyện Mường La (xã Chiềng Lao, Nậm Giôn, Mường Trai, Hua Trai, Ngọc Chiến) và $5 / 27$ xã nghèo thuộc huyện Thuận Châu (xã Chiềng Bôm, Nậm Lầu, Tông Lạnh, Chiềng Pha, Mường Khiêng).

Chọn đối tượng nghiên cứu: theo phương pháp ngẫu nhiên hệ thống

\subsection{Phương pháp và công cụ thu thập số liệu}

Phỏng vấn: sử dụng bộ câu hỏi được thử nghiệm trước khi điêu tra.

Cần đo nhân trắc: Cân điện tử TANITA SC 
330 với độ chính xác $0,1 \mathrm{~kg}$ đo được \% mõ cơ thể. Đo chiều cao đứng sử dụng thước gỗ 3 mảnh có độ chính xác tới $1 \mathrm{~mm}$.

Xét nghiệm máu: Kẽm huyết thanh định lượng theo phương pháp quang phổ hấp phụ nguyên tử (AAS). Vitamin $A$ huyết thanh bằng phương pháp HPLC (WHO, 1996). Nồng độ Ferritin huyết thanh (SF) bằng phương pháp ELISA. Định lượng Hemoglobin $(\mathrm{Hb})$ trong máu bằng phương pháp Cyamethemoglobin, dùng máy Hemocue; Các mẫu đã được phân tích tại labo vi chất, Viện Dinh dưỡng.

2.7. Một số tiêu chuẩn xác định, đánh giá

Chỉ số khối cơ thể (BMI): được tính bằng cân nặng/(chiều cao $)^{2}$ đơn vị $\left(\mathrm{kg} / \mathrm{m}^{2}\right)$.

Đánh giá: Thiếu kẽm xác định khi nồng độ kẽm trong máu (buổi sáng) <10,1 $\mu \mathrm{mol} / \mathrm{L}$ (IZiNCG 2012); thiếu kẽm ở ngưỡng rất cao có YNSKCĐ theo IZiNCG là trên $20 \%$; retinol huyết thanh $<1,05 \mu \mathrm{mol} / \mathrm{l}$ là thiếu vitamin $A$ tiền lâm sàng (VAD - TLS) và nguy cơ; Dự trữ sắt thấp khi ferritin huyết thanh < $30 \mu \mathrm{g} / \mathrm{l}$; Thiếu máu khi hemoglobin < $120 \mathrm{~g} / \mathrm{l}$ (WHO 2001).

\subsection{Biến số, chỉ số nghiên cứu}

- Nồng độ kêm huyết thanh trung bình và tỷ lệ thiếu kẽm chung; theo nhóm tuổi; nhóm đối tượng (cân nặng thấp, CED, BMI, \% mõ cơ thể, thiếu vi chất).

- Yễu tố liên quan đối: các yễu tố nhân khẩu học, tiền sử bệnh tật, tình trạng dinh dưỡng, vi chất dinh dưỡng, tiền sử dùng thuốc

2.9. Phân tích và xử lý số liệu. Sử dụng phần mềm Epi Data 3.1 để nhập liệu và SPSS 18.0 để phân tích. Test kiểm định thống kê là $\chi^{2}$ test, $\mathrm{t}$ test, ANOVA test. Giá trị $\mathrm{p}<0,05$ được xem có ý nghĩa thống kê. Tương quan tuyến tính với nồng độ vitamin $A$, kẽm và hemoglobin phân bố chuẩn (test Pearson) và ferritin phân bố không chuẩn (test Spearman); Hồi qui losgistic đa biến dự đoán yếu tố liên quan.

2.10. Đạo đức nghiên cứu. Nghiên cứu đã được chấp thuận bởi Hội đồng đạo đức của Viện Dinh dưỡng trước khi triển khai, theo quyết định số 1474 /QĐ-VDD ngày 14/09/2018.

\section{KẾT QUẢ NGHIÊN CỨU}

Nghiên cứu đã tiến hành trên 809 đối tượng nghiên cứu (ĐTNC) tại 10 xã của tỉnh Sơn La, trong đó chủ yếu là dân tộc Thái chiếm $86,5 \%$. Tuổi trung bình (TB) là 25,0 $\pm 6,5$. Có 46,6\% ĐTNC thuộc hộ gia đình nghèo; $20,9 \%$ là cận nghèo; $81,7 \%$ ĐTNC có nghề nghiệp chính là làm ruộng; $14,7 \%$ ĐTNC là học sinh.

Bảng 1. Nồng độ kẽm huyêt thanh và tỷ lệ thiêu kẽm ở ĐTNC theo nhóm tuổi (n=809)

\begin{tabular}{|c|c|c|c|c|}
\hline Nhóm tuổi & $\mathbf{n}$ & $\begin{array}{c}\text { Số thiếu } \\
\text { kẽm }\end{array}$ & $\begin{array}{c}\text { Tỷ lệ thiếu kẽm } \\
(\mathbf{\%})^{\mathbf{b}}\end{array}$ & $\begin{array}{c}\text { Nồng độ kẽm huyết thanh } \\
(\mathbf{T B} \pm \mathbf{S D})(\boldsymbol{\mu m o l} \mathbf{m})\end{array}$ \\
\hline $15-24$ tuối & 368 & 309 & $84,0^{\text {b1 }}$ & $9,71 \pm 1,43^{\mathrm{c}}$ \\
\hline $25-35$ tuối & 441 & 393 & 89,1 & $9,43 \pm 1,59$ \\
\hline $15-19$ tuối & 203 & 174 & $85,7^{\mathrm{b} 1}$ & $9,70 \pm 1,24$ \\
\hline $20-24$ tuối & 165 & 135 & 81,8 & $9,72 \pm 1,64$ \\
\hline $25-29$ tuối & 202 & 175 & 86,6 & $9,58 \pm 1,65$ \\
\hline $30-35$ tuối & 239 & 218 & 91,2 & $9,29 \pm 1,52^{\text {a1 }}$ \\
\hline Chung & $\mathbf{8 0 9}$ & $\mathbf{7 0 2}$ & $\mathbf{8 6 , 8}$ & $\mathbf{9 , 5 6} \pm \mathbf{1 , 5 2}$ \\
\hline
\end{tabular}

a) ANOVA-test với ${ }^{1} p<0,05 ;$ b) $\chi^{2}$ test với ${ }^{1} p<0,05 .{ }^{c)}$ t-test ${ }^{2} p<0,01$.

Tỷ lê thiếu kẽm ở ĐTNC là 86,8\%. Có sư khác biêt có YNTK về tỷ lệ thiếu kẽm và hàm lượng kẽm huyết thanh ở phụ nữ $15-35$ tuổi giữa 2 và 4 nhóm tuổi. Nhóm tuổi $30-35$ tuổi có hàm lượng kẽm thấp nhất, khác biệt có YNTK so với 3 nhóm tuổi còn lai (post hoc test, $p<0,05$ ).

Bảng 2. Mối liên quan giữa thiếu kêm với tình trạng dinh dướng và thiếu máu, thiếu vitamin A $(n=809)$

\begin{tabular}{|c|c|c|c|c|c|}
\hline Tình trạng & $\mathbf{n}$ & $\begin{array}{l}\text { Số thiếu } \\
\text { kẽm }\end{array}$ & $\begin{array}{l}\text { Tỷ lệ } \\
(\%)^{a}\end{array}$ & $\begin{array}{c}p^{b} \\
\text { OR }(95 \% \mathrm{CI})\end{array}$ & $\begin{array}{l}\text { Nồng độ kẽm huyết } \\
\text { thanh }(\mu \mathrm{mol} / \mathrm{L})^{\mathrm{c}}\end{array}$ \\
\hline Tình trang CED & 152 & 124 & 81,6 & $0,049^{b 1}$ & $9,80 \pm 1,4^{c 1}$ \\
\hline Bình thường & 657 & 578 & 88,0 & $0,61(0,38-0,97)$ & $9,50 \pm 1,5$ \\
\hline VAD và nguy cơ & 314 & 288 & 91,7 & $0, \mathbf{0 0 1}^{\mathrm{b} 3}$ & $9,31 \pm 1,4^{c 3}$ \\
\hline Bình thường & 495 & 414 & 83,6 & $2,17(1,34-3,46)$ & $9,71 \pm 1,6$ \\
\hline Thiếu máu & 210 & 187 & 89,0 & 0,312 & $9,35 \pm 1,4^{\mathrm{c} 1}$ \\
\hline Bình thường & 599 & 515 & 86,0 & $1,33(0,81-2,17)$ & $9,63 \pm 1,5$ \\
\hline
\end{tabular}

b) $\chi^{2}$ test; c) t-test; ${ }^{1)} \mathrm{p}<0,05{ }^{3)} \mathrm{p}<0,001$

Có khác biệt có YNTK về tỷ lệ thiếu kẽm ở nhóm CED và nhóm VAD -TLS và nguy cơ so với nhóm bình thường $(\mathrm{p}<0,05)$. Giá trị TB kẽm huyết thanh ở nhóm CED, VAD -TLS và nguy cơ, thiếu máu 
khác biêt có YNTK so với nhóm bình thường $(\mathrm{p}<0,05)$.

Bảng 3. Hồi qui logistic đa biến dự đoán các yêu tô liên quan với thiêu kẽm (n=809)

\begin{tabular}{|c|c|c|c|c|c|c|c|c|c|}
\hline \multirow{2}{*}{\multicolumn{3}{|c|}{$\begin{array}{l}\text { Các yếu tố trong mô hình } \\
\text { (Biến độc lập) }\end{array}$}} & \multicolumn{2}{|c|}{ UC* } & \multirow{2}{*}{\multicolumn{2}{|c|}{$\begin{array}{c}\text { OR } \\
\text { (Hiệu chỉnh) }\end{array}$}} & \multirow{2}{*}{\multicolumn{2}{|c|}{$95 \% \mathrm{CI}$}} & \multirow{2}{*}{ p } \\
\hline & & & $\beta$ & SE & & & & & \\
\hline \multicolumn{3}{|c|}{ Tình trạng CED (CED/bình thường*) } & $-0,56$ & 0,25 & 0,57 & & 0,35 & 0,93 & 0,026 \\
\hline \multicolumn{3}{|c|}{$\begin{array}{c}\text { Tình trạng vitamin } A \text { (VAD - TLS và nguy } \\
\text { cơ VAD-TLS/bình thường*) }\end{array}$} & 0,86 & 0,24 & 2,37 & & 1,48 & & 0,000 \\
\hline \multicolumn{3}{|c|}{$\begin{array}{l}\text { Trình độ học vấn (mù chũ̃ và cấp 1/từ } \\
\text { cấp } 2 \text { trở lên) }\end{array}$} & 0,44 & 0,25 & 1,55 & & 0,96 & 51 & 0,076 \\
\hline \multicolumn{3}{|c|}{ Sốt trong 4 tuânn qua (có sốt/không sốt*) } & $-0,52$ & 0,23 & 0,60 & & 0,38 & 0,94 & 025 \\
\hline \multicolumn{9}{|c|}{ 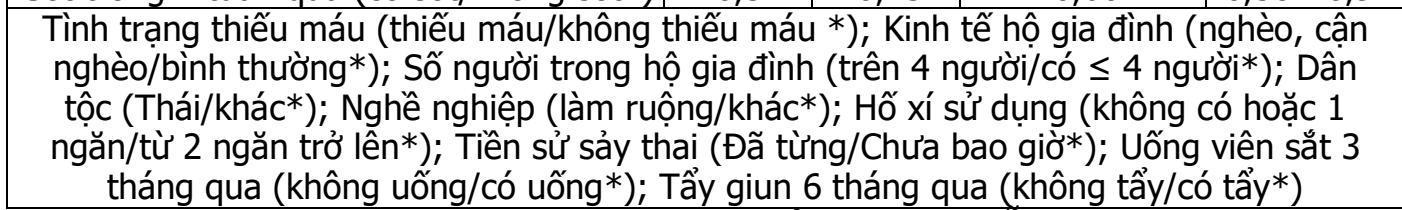 } & $>0,05$ \\
\hline \multicolumn{10}{|c|}{ 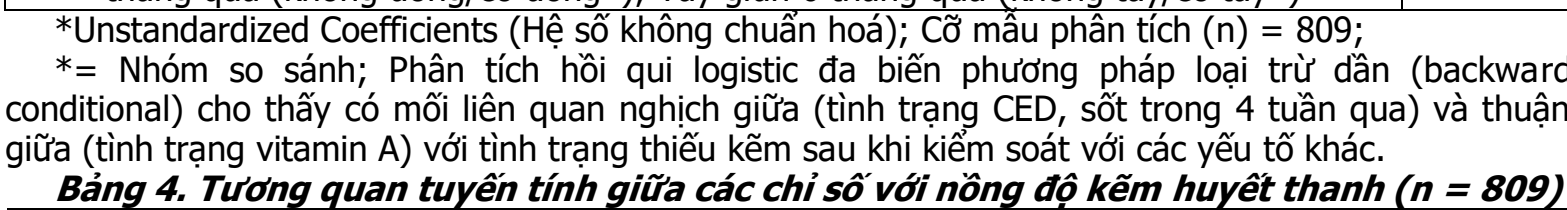 } \\
\hline $\begin{array}{l}\text { Các Biến } \\
\text { độc lập }\end{array}$ & $\begin{array}{l}\text { Retinol huyết } \\
\text { thanh }\end{array}$ & & $\begin{array}{l}\text { moglobi } \\
\text { thanh }\end{array}$ & & $\begin{array}{l}\text { erritin } \\
\text { êt thành }\end{array}$ & & MI & & $\begin{array}{l}\text { mỡ cơ } \\
\text { thể }\end{array}$ \\
\hline Tương quan & & & & & & & & & \\
\hline & & & 0,106 & & 12 & & & & \\
\hline$p$ & 0,000 & & 0,003 & & 0,735 & & 000 & &, 002 \\
\hline
\end{tabular}

2*: Tương quan Pearson; ${ }^{3 *}$ Tương quan Spearman

Nồng độ kẽm huyết thanh có tương quan tuyến tính thuận chiều tới hàm lượng retinol huyết thanh, hemoglobin; và ngược chiều với chỉ số BMI và \% mõ cơ thể $(p<0,01)$. tuy nhiên những sự tương quan này là sự tương quan yếu (với $r$ thấp nhất 0,106 cao nhất là 0,138 ).

Bảng 5. Tương quan đa biến tuyến tính một số chỉ số với nồng độ kêm huyêt thanh

\begin{tabular}{|c|c|c|c|c|}
\hline \multirow{2}{*}{$\begin{array}{c}\text { Các yếu tố trong mô hình } \\
\text { (Biến độc lập) }\end{array}$} & \multicolumn{2}{|c|}{ Hề số không chuấn hóa } & \multirow{2}{*}{$\begin{array}{l}\boldsymbol{\beta}(\mathrm{Hiêeu} \\
\text { chinh) }\end{array}$} & \multirow[b]{2}{*}{$\mathbf{p}$} \\
\hline & $\beta$ & SE & & \\
\hline Chỉ số \% mỡ cơ thế & $-0,04$ & 0,01 & $-0,14$ & 0,000 \\
\hline Hemoglobin & 0,01 & 0,00 & 0,10 & 0,006 \\
\hline Ferritin huyết thanh & 0,00 & 0,00 & $-0,01$ & 0,799 \\
\hline Retinol huyết thanh & 0,64 & 0,14 & 0,16 & 0,000 \\
\hline
\end{tabular}

Có tương quan tuyến tính thuận chiều giữa (hemoglobin, retinol huyết thanh) và ngược chiều giữa $\%$ mõ cơ thể với hàm lượng kẽm (linear regrestion, $R=0,22 ; R^{2}=0,042, p<0,001$ ).

\section{BÀN LUẬN}

Tỷ lệ thiếu kẽm ở ĐTNC là 86,8\% trong đó lứa tuổi cao nhất là nhóm 30 - 35 tuổi $(91,2 \%)$, ở ngưỡng rất cao (theo IZiNCG >trên 20\%) có YNSKCĐ; cao hơn tỷ lệ này ở PNTSĐ năm 2010 $(67,2 \%)[3]$; và ở PNTSĐ ở vùng nông thôn $(60,3 \%)$, cũng như cao hơn ở vùng miền núi $(73,4 \%)$ trong điều tra ba vùng năm 2015 [4]; đồng thời, cao hơn tỷ lệ ở PNTSĐ trong Tổng điều tra toàn quốc 2019 (63,5\%), và tỷ lệ ở cũng đối tượng này vùng miền núi phía Bắc $(81,9 \%)$ [5]; Nồng độ kẽm huyết thanh TB ở ĐTNC là $(9,56 \pm$ $1,5 \mu \mathrm{mol} / \mathrm{L}$ ), cao hơn nồng độ kẽm ở PNTSĐ miền núi $(8,1 \mu \mathrm{mol} / \mathrm{L})$ và vùng nông thôn $(9,3 \mu \mathrm{mol} / \mathrm{L})$ năm 2015 [4]; Điều đó cho thấy mặc dù nồng độ kẽm huyết thanh đã có sự tăng lên nhưng tỷ lệ thiếu kẽm trong gần 2 thập kỷ qua thay đổi không đáng kể, cho thấy khẩu phần kẽm trong chế độ ăn của phụ nữ miền núi đã được cải thiện; tuy nhiên tỳ lệ thiếu kẽm của PNTSĐ vùng Sơn La nói riêng và Việt Nam nói chung vẫn là vấn đề nghiêm trọng có YNSKCĐ, cần có giải pháp tích cực và tổng thể trong việc cải thiện, bao gồm cải thiện chế độ ăn (tăng cường sử dụng thức ăn nguồn gốc động vật giàu kẽm như thịt, cá, hải sản) và cần bổ sung kẽm định kỳ cho đối tượng nguy cơ cao để có thể cải thiện nhanh và bền vững tình trạng thiếu kẽm tại các vùng miền núi, đặc biệt vùng khó khăn, vùng nghèo.

Thiếu sắt có thể cùng tồn tại với sự thiếu hụt các nguyên tố vi lượng khác như kẽm, thường gặp ở các nước đang phát triển. Kẽm đóng vai 
trò là chất xúc tác trong quá trình chuyển hóa sắt trong hoạt động của enzym khử nước axit alpha-aminolevulinic, có vai trò trong quá trình tổng hợp heme (Ece A, 1997); Do đó, kết quả nghiên cứu tại Sơn La là hợp lý khi có tương quan thuận giữa nồng độ hemoglobin với kẽm huyết thanh; vì theo nghiên cứu của Soliman năm 2019 cho thấy nồng độ kẽm huyết thanh ở bênh nhân thiếu máu do thiếu sắt thấp hơn so với bệnh nhân không thiếu máu; lý do là sự hấp thu sắt bị suy giảm có thể do giảm các nguyên tố vi lượng như kẽm, được tìm thấy trong cấu trúc của các enzym điều phối hoặc xúc tác quá trình chuyển hóa sắt. Mối liên quan giữa thiếu kẽm và thiếu sắt có thể do thiếu dinh dưỡng của cả hai nguyên tố hoặc do kém hấp thu. Điều đó cho thấy nên can thiệp bổ sung cả sắt và kẽm trên đối tượng thiếu máu thiếu sắt thay vì chỉ bổ sung sắt đởn thuần.

Kẽm là một nguyên tố vi lượng cần thiết cho sự tăng trưởng, phát triển và duy trì chức năng miễn dịch [6]; khi nhiếm khuẩn cơ thể sẽ huy động kễm tham gia vào quá trình miễn dịch. Kết quả nghiên cứu của chúng tôi cho thây có mối liên quan nghịch chiều giữa tình trạng sốt với với tình trạng thiếu kẽm; có thể lý giải khi sốt, có thể sẽ huy động kẽm tham gia vào phản ứng chống viêm, làm nồng độ kẽm trong huyết thanh tăng lên. Mối liên quan thuận chiều giữa học vấn của ĐTNC với tình trạng thiếu kẽm được cho rằng trình độ học vấn thấp sẽ ảnh hưởng đến điều kiện kinh tể, cũng như kiến thức thực hành dinh dưỡng, dẫn đến chất lượng bữa ăn của đối tượng không đảm bảo.

Trong nghiên cứu này cho thấy có liên quan nghịch chiều giữa thiếu kẽm và phần trăm mỡ cơ thể, tình trạng CED, có thể được lý giải bởi chức năng của mô mõ được coi là một cơ quan nội tiết và sự dư thừa của nó làm tổn hại đến phản ứng miễn dịch và sự chuyển hóa của các hormone và chất dinh dưỡng [7]. Sự tích tụ chất béo nội tạng góp phần làm tăng tổng hợp cortisol, do đó gây ra biểu hiện metallothionein và Zip14, là những protein góp phần làm giảm nồng độ kẽm trong huyết tương [7]. Một số nghiên cứu trên thế giới đã cho thây mối liên quan giữa thừa cân, béo phì với nồng độ kẽm huyết thanh thấp (Canatan $\mathrm{H}$, 2004).

Tình trạng kẽm ảnh hưởng đến quá trình chuyển hóa vitamin $A$, bao gồm cả sự hấp thụ, vận chuyển và sử dụng nó [8]. Hai cơ chế thông thường giải thích sự phụ thuộc này liên quan đến 1) vai trò điều tiết của kẽm trong vận chuyển vitamin $\mathrm{A}$ qua trung gian tổng hợp protein, và 2 ) sự chuyển đổi oxy hóa của retinol thành retinal đòi hỏi hoạt động của enzyme retinol dehydrogenase phụ thuộc vào kẽm điều đó đã lý giải tương quan tuyến tính của kẽm với hàm lượng vitamin $A$ huyết thanh và mối liên quan giứa tình trạng thiếu kẽm với tình trạng thiếu vitamin $A$ ở kết quả nghiên của chúng tồi. Từ kết quả trên cho thấy, để cải thiện tình trạng thiếu kẽm, cần cải thiện tình trạng thiếu vi chất dinh dưỡng đặc biệt là tình trạng thiếu máu và thiếu vitamin $A$; ngoài các can thiệp phòng chống thiếu vi chất dinh dưỡng như các giải pháp giáo dục truyền thông, nâng cao chất lượng bữa ăn, cần bổ sung kẽm bằng nhiêu giải pháp (như bố sung kẽm định kỳ đường uống hay tăng cường sử dụng thực phẩm bổ sung kẽm, vitamin $A$ và sắt) để đảm bảo tính bền vững trong cải thiện tình trạng thiếu kẽm.

\section{KẾT LUẬN}

Tỷ lệ thiếu kẽm ở ĐTNC là 86,8\%, rất cao là vấn đề có YNSKCĐ. Nồng độ kẽm huyết thanh trung bình là $9,56 \pm 1,5 \mu \mathrm{mol} / \mathrm{L}$. Tỷ lệ thiếu kẽm ở nhóm 15 - 24 là $84,0 \%$ thấp hơn có YNTK so với nhóm $25-35$ tuổi $(89,1 \%)$. Có tương quan thuận chiều giữa nồng độ hemoglobin và retinol huyết thanh với nồng độ kẽm huyết thanh. Có liên quan giữa tình trang $C E D$, tình trạng sốt và tình trạng vitamin A đối với tình trạng thiếu kẽm.

\section{TÀI LIẸU THAM KHẢO}

1. Wessells KR, Brown KH. Estimating the global prevalence of zinc deficiency: results based on zinc availability in national food supplies and the prevalence of stunting. PLoS One, 2012; 7(11).

2. Engle-Stone R, Ndjebayi AO. Stunting prevalence, plasma zinc concentrations, and dietary zinc intakes in a nationally representative sample suggest a high risk of zinc deficiency among women and young children in Cameroon. The Journal of Nutrition. 2014; 144(3): 382-91.

3. Laillou A, Pham TV et al. Micronutrient deficits are still public health issues among women and young children in Vietnam. PLoS One 2012; 7, e34906

4. Viện Dinh dưỡng. Đánh giá tình trạng thiếu máu, thiếu một số vi chất dinh dưỡng của phụ nữ và tré em 6 - 59 tháng tại vùng thành thị, nông thôn và miên núi năm 2014 - 2015. Báo cáo đề tài nghiên cứu cấp Viện 2015.

5. Viện Dinh dưỡng. Báo cáo sơ bộ kết quả Tổng điểu tra Dinh dưỡng toàn quốc 2019 - 2020. 2021.

6. Read SA, Obeid S. The Role of Zinc in Antiviral Immunity. Adv Nutr, 2019. 10(4): 696-710.

7. Morais JBS, Severo JS et al. Association between Cortisol, Insulin resistance and Zinc in obesity: a Mini-Review. Biological Trace Element Research, 2019. 191: 323-330.

8. Christian P, West KPJ, Interactions between zinc and vitamin A: an update. Am J Clin Nutr, 1998. 68: p. 435S-441S. 